\title{
Family Background and Environment, Psychological Distress, and Juvenile Delinquency
}

\author{
Tony Cassidy \\ University of Ulster, Coleraine, UK. \\ Email: t.cassidy@ulster.ac.uk \\ Received August 31 ${ }^{\text {st }}$, revised September 30 ${ }^{\text {th }}$, 2011; accepted October $28^{\text {th }}, 2011$.
}

\begin{abstract}
The relationship between youth offending and family background is still unclear in the literature. This study explored the role of family factors and psychological distress in relation to delinquency and youth offending to try and explicate the relative importance of family structure, family relations, and psychological distress. The study used the Brief Symptom Inventory, the Family Environment Scale, and the Delinquency Scale in a structured interview format to measure psychological distress, family structure and relations, and levels of youth offending, in 219 older children and adolescents aged between 12 - 17 years living in areas associated with high levels of youth offending in the UK. Analysis involved correlations, hierarchical multiple regression and analysis of variance. Family relations were the best predictors of delinquency and were also correlated with psychological distress. The relationship between delinquency and psychological distress indicated that participants with more psychological distress were less likely to be involved in criminal behaviour. The study supports the conclusion that youth offending and psychological distress are both influenced by a range of factors in the family, but may be unrelated to each other.
\end{abstract}

Keywords: Juvenile Delinquency, Family Background, Family Structure, Family Relations, Mental Health

\section{Introduction}

Young offenders are those law breakers who fall between a minimum age of 10 years old and who are still under 18 years old, and are dealt with by the juvenile justice system in most countries. The concept of a juvenile delinquent, which includes behaviours that would not be considered unlawful and is therefore broader than the concept of young offender, evolved towards the end of the $19^{\text {th }}$ Century to distinguish between adults and children in the criminal justice system. It originates from a quasi-medical model (Blackburn, 1993) and this model of the young offender as ill and in need of intervention has had a major impact on the treatment of young offenders. As an explanation for offending behaviour however it has been controversial and is still the subject of debate in the literature. Hirsch (1937) in his book "Dynamic Causes of Juvenile Crime" posited 4 categories of causation; heredity, environment, accident, and genius. By genius he seems to suggest that the absence of social intelligence is associated with crime, and by accident he meant anything that cannot be included under heredity, environment or genius. He concluded that delinquency is unlikely to be caused by any single factor, and in his more detailed analysis he identified, broken homes, family position, defective intelligence, and enuresis as important causal factors.

Research on parental separation and delinquency is not new (e.g. Glueck \& Glueck, 1950), however findings have been equivocal. Fergusson, Horwood and Lynkskey (1994) found little effect of parental separation while Lindner, Stanley-Hagen and Cavanaugh Brown (1992) found a significant increase in delinquency following divorce. However the latter finding more closely reflects the lay view often reflected in media coverage which has been vociferous in linking delinquency and nontraditional families. More recently Mack et al. (2007) found that family type had no predictive relationship with delinquency and the only significant effect was for maternal attachment. What the debate often fails to do, apart from accurately reflecting the research evidence, is to distinguish between the various forms of non-traditional families. For example the term single parent family is used as a generic term to describe family structures that have derived in various ways, separation, divorce, nonmarried partners who have split up, and parents who never had a long term live in partner. In addition factors to do with relationships within the family, parent-child relationships, and parenting behaviour are often ignored. Factors such as increased conflict and reduced cohesion (Haapasalo \& Tremblay, 1994), and increased pressure and demands on children (Hetherington, Cox, \& Cox, 1985), are associated with family break up. However divorce can either increase or decrease these problems which may partly explain the equivocal findings. In a longitudinal study Pagani et al. (1998) suggest that boys who experience remarriage between the ages of 11 - 15 were most at risk for delinquency, however this was partly explained through reduced expressiveness in the family. Smith and Farrington (2004) in a complex study across three generations found continuity in antisocial behaviour which was partly mediated by parenting behaviour. Parental conflict and authoritarian parenting were related to antisocial behaviour in children. Farrington (2005) in a review of research identifies a long list of psychosocial risk factors for antisocial behaviour including poor parental relationships and parenting, and peer, neighbourhood and school context. He proposes the Integrated Cognitive Antisocial Potential (ICAP) theory which describes a process of personsituation interaction largely based on a social learning model of antisocial behaviour. There seems to be strong evidence that antisocial behaviour and delinquency has a complex, causal etiology based in social learning and involving a range of factors in the family (Stouthamer-Loeber \& Loeber, 1988; StouthamerLoeber et al., 2002a, 2002b; Tremblay et al., 1992; Farrigton, 2005). Identifying the predictive correlates at a sufficient level of specificity enables the design and implementation of preven- 
tive strategies.

There is a demonstrable sex difference in delinquency with boys more frequently involved than girls (Fitzgerald, 2003). In addition girls who do become delinquent are less likely to demonstrate aggressive or violent behaviour. It appears that girls who are bullied and have lower commitment to school are more susceptible to delinquency while the same factors do not differentiate delinquent versus non-delinquent boys (Fitzgerald, 2003). This is important for sex based interventions.

In addition to the non-traditional family myth there is a pervasive belief represented in the media that delinquency is closely linked with mental health problems. The evidence is again equivocal. Nader, Singleton and Meltzer (2003) suggest that the prevalence of psychotic and affective disorders among young offenders in the UK is low (8\% - 10\% for males and 9\% for females) but the prevalence for neurotic disorders was high ( $41 \%$ for males and $67 \%$ for women). The same study shows a high prevalence of personality disorder but since a key element of the definition of personality disorder is aggressive or antisocial behaviour it seems to add little to our understanding of the problem. In much of the literature the terms mental illness are used reflecting a medical model perspective which is problematic for explanations of offending behaviour since the literature largely supports a social learning explanation (Farrington, 2005; Smith \& Farrington, 2004; Mack et al., 2007). In order to take a stance on this the current author prefers to use the terms psychological distress.

Assumptions about the heritability of juvenile crime are one of the illogical conclusions drawn from the general belief about family links to crime. It is generally accepted that early claims about the heritability of delinquency such as Hirsch (1937) were more a function of Nativistic bias in the theorist than anything in the evidence base presented. There have been many critiques of the limitations of behavioural genetics particularly in regard to crime (Taylor, 2001) yet despite the social, psychological and environmental confounds in their studies some authors still choose to argue a genetic explanation (Kakar, 2005; Tuvblad, Grann \& Lichtenstein, 2006). Moffitt (2005) argues that behavioural genetic methods are necessary to move research on antisocial behaviour beyond the identification of risk factors to the establishment of causality. Theorists adopting this approach are willing to admit that perhaps $50 \%-60 \%$ of the variance in antisocial behaviour may have environmental causes based on concordance estimates of $40 \%-50 \%$ for genetic sharing. This assumes that the concordance estimates prove a genetic influence an assumption that is by no means accepted by the majority of researchers. In effect the introduction of a genetic argument in the field seems to be a distraction from efforts of identify and intervene in preventing antisocial behaviour. Perhaps this "genetic" component can be better explained through social learning as demonstrated in Smith and Farrington's (2004) intergenerational study. The presence of an antisocial relative as a social learning model would seem to offer a more reasonable explanation for increased prevalence of delinquency than the presence of some inherited disposition (Carey, 1992).

Juvenile delinquency is a major problem in most societies and those involved in the justice system face the ongoing dilemma of designing and implementing interventions in the context of erroneous media opinion about causation and a confusing evidence base. There is still a lack of clarity about the role of the family and mental health in causing and maintaining juvenile delinquency. The current study aims to explore the relationship between factors of family structure, family rela- tions, psychological distress and juvenile delinquency.

The specific predictions are:

1) Family background and family relations will be related to both psychological distress and juvenile delinquency, but through different pathways.

2) Psychological distress will not be significantly related to juvenile delinquency.

\section{Method}

\section{Design}

The study used a quasi-experimental survey design with structured interview and questionnaire data collection techniques to investigate the relationship between family background, family relations, psychological distress and juvenile delinquency in a sample of 219 participants living in areas with high levels of reported crime.

\section{Participants}

These were 219 young people (147 males and 72 females) aged between 13 - 18 years. Of these 62 were aged $13-14$ years, 84 were 15 - 16 years, and 73 were 17 - 18 years. In terms of home background, 94 had both parents still together, 52 had been born into a single parent situation, and 73 had experienced a family break up (69 because parents were separated or divorced, and 4 because one parent had died). Sampling was a mix of purposive and snowball techniques through targeting youth centres in a target area.

\section{Measures}

A structured interview format was used to obtain information about age, sex, parental situation (single parent, separated, divorced, widowed), age at which family break up occurred, current family structure (both natural parents, single parent, one parent plus partner), number of brothers or sisters, birth order, and if they had any relative who had been involved in criminal activity. In addition three standardised questionnaires were used to measure, 1) family environment, 2) delinquency, and 3) psychological distress.

1) Family Environment Scale (Moos \& Moos, 1986). This is a 90 item scale which measures 10 first order factors of family environment, cohesion (Alpha $=.86$ ), expressiveness (Alpha $=.82)$, conflict (Alpha $=.87)$, independence (Alpha $=.84$ ), achievement orientation (Alpha $=.89$ ), intellectual-cultural orientation (Alpha $=.80$ ), active-recreational orientation (Alpha $=.83$ ), moral-religious orientation (Alpha $=.81$ ), organisation (Alpha $=.92)$, and control (Alpha $=.90)$. The scales are scored so that a higher score indicates more experience of the specific factor within the family. The 10 first order factors can be grouped into 3 second order factors, 1) relationships (cohesion, expressiveness, and conflict), 2) personal growth (independence, achievement orientation, intellectual-cultural orientation, active-recreational orientation, and moral-religious orientation) and 3) systems maintenance (organisation and control).

2) The Delinquency Scale (LeBlanc \& Tremblay, 1988): This is a 27 item scale measuring 4 dimensions of delinquent behaviour, physical aggression, stealing, vandalism, and alcohol and drug use. The scale can also be used as a single measure of delinquency. The scale has been used in a number of studies (Haapasalo \& Tremblay, 1994; Pagani et al., 1998) and has shown good reliability and validity. The Cronbach Alpha scores in this study were, physical aggression (Alpha $=.86$ ), 
stealing $($ Alpha $=.88)$, vandalism $($ Alpha $=.91)$, alcohol $/$ drug use (Alpha $=.89)$, total scale (Alpha $=.87)$.

3) The Brief Symptom Inventory (Derogatis, 1993): This is a 53 item scale derived from the Symptom Checklist 90 (Derogatis, 1977) which measures 10 dimensions of symptoms of psychopathology, somatisation (Alpha = .92), obsessivecompulsive (Alpha $=.94$ ), interpersonal sensitivity (Alpha $=.97$ ), depression (Alpha $=.89$ ), anxiety (Alpha $=.88$ ), hostility (Alpha $=.85)$, phobic anxiety (Alpha $=.92)$, paranoid ideation (Alpha $=.84$ ), psychoticism (Alpha $=.87$ ), and suicide ideation (Alpha $=.86)$. The scale gives three summary indexes, a) General Severity Index (GSI) - a weighted frequency score based on the sum of ratings on each symptom, b) Positive Symptom Total (PST) - a frequency count of the number of symptoms, and c) Positive Symptom Distress Index (PSDI)-a score reflecting the intensity of the distress. Previous studies have used measures such as the General Health Questionnaire (GHQ) (Goldberg, 1972) which produces an overall measure of psychological distress based on a combination of symptoms of depression, anxiety and somatisation. This excludes psychotic symptoms and symptoms of hostility and interpersonal sensitivity which might be more likely to be associated with criminality. In the current study the authors decided to use the BSI because it includes a wider range of symptoms and is therefore more comprehensive than the GHQ but still allows a composite measure of psychological distress.

\section{Procedure}

Participants were accessed via a number of youth centres following approval from youth leaders and local councils. Initially youths attending centres were approached by youth leaders and asked to participate. Snowball sampling was then used to try and reach those who did not attend or were irregular attendees. The initial target number was 500, however only 288 participants were accessed and provided with questionnaires. Of these 219 completed questionnaires were collected, a response rate of $76 \%$. This is a difficult population to sample and it is difficult to say if those who did not respond represent a specific sub-sample. This may affect the ability to generalise findings though the fact that approximately one third of the sample were obtained through the use of snowball sampling should reduce the problem. All participants were briefed on the study requirements via an information sheet and asked for their voluntary participation. It was explained that data would remain anonymous and be treated in confidence and that they could withdraw at any time. All data was entered into SPSS for analysis. Analysis involved one way analysis of variance (Anova) was used to test for main effects on the independent variables. Pearson Correlations to test for relationships and Structural Equation Modelling was used to test the fit of a Path Model.

\section{Results}

Anova was used to test for main effects on age, sex, family structure, and the presence of another family member who had been involved in crime.

There were significant age effects for physical aggression $(\mathrm{F}(2,216)=11.47, \mathrm{p}<.001)$, stealing $(\mathrm{F}(2,216)=8.54, \mathrm{p}<.001)$, vandalism $(\mathrm{F}(2,216)=10.43, \mathrm{p}<.001)$, alcohol/drug use $(\mathrm{F}(2,216)$ $=43.16, \mathrm{p}<.001)$, total delinquency $(\mathrm{F}(2,216)=21.54, \mathrm{p}<.001)$, family relations $(\mathrm{F}(2,216)=3.75, \mathrm{p}<.05)$, personal growth $(\mathrm{F}(2,216)=6.03, \mathrm{p}<.01)$, positive symptom index $(\mathrm{F}(2,216)$ $=4.41, \mathrm{p}<.01)$, overall distress $(\mathrm{F}(2,216)=3.09, \mathrm{p}<.05)$, and general severity index $(\mathrm{F}(2,216)=3.22, \mathrm{p}<.05)$. The means and standard deviations are shown in Table 1.

There were significant main effects for sex on physical aggression $(\mathrm{F}(2,216)=30.51, \mathrm{p}<.001)$, stealing $(\mathrm{F}(2,216)=6.59$, $\mathrm{p}<.01)$, and total delinquency $(\mathrm{F}(2,216)=11.12, \mathrm{p}<.001)$.

In terms of family structure participants were divided into three groups, those whose original family was still intact, those who had always been in a single parent family, and those whose parents had separated or were divorced. On this variable there were significant main effects for stealing $(F(2,216)=6.45$, $p$ $<.01)$, alcohol/drug use $(\mathrm{F}(2,216)=3.89, \mathrm{p}<.05)$, family relations $(\mathrm{F}(2,216)=8.78, \mathrm{p}<.001)$, positive symptom index $(\mathrm{F}(2$, $216)=5.54, \mathrm{p}<.01)$, overall distress $(\mathrm{F}(2,216)=7.82, \mathrm{p}$ $<.001)$, and general severity index $(\mathrm{F}(2,216)=8.19$, $\mathrm{p}<.001)$.

Of the total participants, 60 reported that at least one member of their family had been involved in crime. Using this as an independent variable, significant main effects were found on physiccal aggression $(\mathrm{F}(2,216)=30.53, \mathrm{p}<.001)$, stealing $(\mathrm{F}(2,216)$ $=27.37, \mathrm{p}<.001)$, vandalism $(\mathrm{F}(2,216)=53.31, \mathrm{p}<.001)$,

Table 1.

Means and standard deviations for delinquency, family environment and psychological distress across age, sex, and family structure.

\begin{tabular}{|c|c|c|c|c|c|c|c|c|c|c|}
\hline & $\begin{array}{c}13-14 \mathrm{yr} \\
\mathrm{N}=62\end{array}$ & $\begin{array}{c}15-16 \mathrm{yr} \\
\mathrm{N}=84\end{array}$ & $\begin{array}{c}\text { 17+ years } \\
\mathrm{N}=73\end{array}$ & $\begin{array}{c}\text { Males } \\
\mathrm{N}=147\end{array}$ & $\begin{array}{c}\text { Females } \\
\mathrm{N}=72\end{array}$ & $\begin{array}{c}\text { Intact family } \\
\mathrm{N}=94\end{array}$ & $\begin{array}{l}\text { Single family } \\
\qquad \mathrm{N}=52\end{array}$ & $\begin{array}{c}\begin{array}{c}\text { Divorced } \\
\text { family } \\
\mathrm{N}=73\end{array} \\
\end{array}$ & $\begin{array}{c}\text { No family } \\
\text { crime } \\
\mathrm{N}=159\end{array}$ & $\begin{array}{c}\text { Family } \\
\text { crime } \mathrm{N}=60\end{array}$ \\
\hline & Mean (Sd) & Mean (Sd) & Mean (Sd) & Mean (Sd) & Mean (Sd) & Mean (Sd) & Mean (Sd) & Mean (Sd) & Mean (Sd) & Mean (Sd) \\
\hline Physical aggression & 10.5 (2.9) & $12.6(3.6)$ & $13.3(3.7)$ & $13.1(3.4)$ & $10.4(3.4)$ & 11.9 (2.9) & $12.9(4.0)$ & $12.1(4.0)$ & $11.4(3.4)$ & $14.3(3.4)$ \\
\hline Stealing & $11.6(4.3)$ & $13.9(4.2)$ & $14.3(3.7)$ & $13.9(3.9)$ & $12.4(4.4)$ & $12.6(3.9)$ & $12.9(3.6)$ & $14.8(4.5)$ & 12.5 (3.6) & $15.7(4.8)$ \\
\hline Vandalism & $7.6(2.1)$ & $9.7(2.9)$ & $9.2(3.0)$ & $9.1(2.8)$ & $8.7(2.9)$ & $9.2(2.8)$ & $8.3(2.9)$ & $9.1(2.9)$ & $8.2(2.3)$ & $11.0(3.1)$ \\
\hline Alcohol/Drug & $5.3(2.6)$ & $8.4(2.3)$ & $9.1(2.5)$ & $7.9(2.7)$ & $7.3(3.1)$ & $7.7(2.8)$ & $6.9(2.9)$ & $8.3(2.9)$ & $7.3(2.9)$ & $8.9(2.4)$ \\
\hline Total Delinquency & $35.1(10.2)$ & $44.5(10.4)$ & $45.8(10.2)$ & $44.0(10.7)$ & $38.8(11.4)$ & 41.5 (10.1) & $41.0(10.8)$ & $44.3(12.5)$ & $39.4(10.3)$ & $49.9(9.8)$ \\
\hline Family relations & $16.4(5.3)$ & $18.9(6.9)$ & $18.8(5.7)$ & $18.2(6.1)$ & $18.1(6.4)$ & $19.9(6.9)$ & $18.4(4.4)$ & $15.4(6.8)$ & $22.4(6.3)$ & $16.6(5.3)$ \\
\hline Systems maintenance & $10.9(4.8)$ & $12.7(5.4)$ & $12.5(5.7)$ & $12.3(4.7)$ & $11.8(6.5)$ & $11.9(4.4)$ & $13.2(5.0)$ & $11.6(6.6)$ & $13.6(4.5)$ & $11.6(5.6)$ \\
\hline Personal growth & $14.5(6.2)$ & $17.4(7.5)$ & $18.7(7.4)$ & $17.1(7.4)$ & $16.9(7.0)$ & $16.3(5.9)$ & 18.5 (6.9) & $16.9(8.9)$ & $19.9(7.7)$ & $15.9(6.8)$ \\
\hline Positive Symptom index & $7.7(2.1)$ & $6.4(3.2)$ & $7.0(2.5)$ & $6.9(2.8)$ & $7.1(2.7)$ & $7.0(2.1)$ & $7.9(3.0)$ & $6.3(2.8)$ & $6.7(3.1)$ & $7.6(2.3)$ \\
\hline Distress index & $4.6(3.9)$ & $3.3(3.5)$ & $3.3(2.9)$ & $3.6(3.4)$ & $3.8(3.8)$ & $3.2(3.5)$ & $5.3(3.7)$ & $3.0(3.0)$ & $3.9(2.1)$ & $4.3(3.7)$ \\
\hline General Severity Index & $.80(.68)$ & $.58(.60)$ & $.56(.51)$ & $.62(.59)$ & $.66(.64)$ & $.57(.60)$ & $.92(.65)$ & $.52(.51)$ & .69 (.57) & . $75(.64)$ \\
\hline
\end{tabular}


alcohol/drug use $(\mathrm{F}(2,216)=15.81, \mathrm{p}<.001)$, total delinquency $(\mathrm{F}(2,216)=46.13, \mathrm{p}<.001)$, family relations $(\mathrm{F}(2,216)$ $=46.09, \mathrm{p}<.001)$, systems maintenance $(\mathrm{F}(2,216)=6.52, \mathrm{p}$ $<.01)$, and personal growth $(\mathrm{F}(2,216)=14.17, \mathrm{p}<.001)$.

The relationship between delinquency, family environment and psychological distress was explored using Pearson correlations and is shown in Table 2. Total delinquency, physical aggression, vandalism, stealing, and alcohol/drug use were negatively correlated with the family environment dimensions of family relations, systems maintenance and growth, and also negatively correlated with the three overall measures of psychological distress from the BSI.

The next stage in analysis was to try and identify the significant predictors of delinquency and psychological distress using hierarchical multiple regression analysis (HMRA). This is shown in Table 3. All categorical variables were re-coded and entered as dummy variables in the regression.

The significant predictors of total delinquency were the family environment dimensions of personal growth and systems maintenance, and the general severity of symptoms index from the BSI which were negative indicators, having a member of family involved in crime which was a positive indicator, and sex and age, accounting for a total of $47 \%$ of the variance. When the separate dimensions of delinquency were considered separately, physical aggression was negatively predicted by personal growth, general severity index, sex and family size, and positively indicated by having a family member involved in crime and age, accounting for $47 \%$ of the variance. For stealing, personal growth, family relations, systems maintenance, and family size were the negative predictors, and birth order, age, family structure (intact, single parent or divorced), and having a family member involved in crime were positive predictors, accounting for $41 \%$ of the variance. For vandalism, having a family member involved in crime was the only positive predictor, and family relations and personal growth were negative predictors accounting for $30 \%$ of the variance. Age and birth order were the positive predictors of alcohol/drug use and systems maintenance and personal growth were negative predictors, accounting for $50 \%$ of the variance. Psychological distress as measured by the general severity index of the BSI was negatively predicted by family relations and birth order, and positively predicted by alcohol/drug use and having a family member involved in crime, accounting for $44 \%$ of the variance. Fi- nally family relations was negatively predicted by vandalism, stealing, and having a family member involved in crime, and positively predicted by family size, accounting for $30 \%$ of the variance.

The AMOS Structural Equation Modelling software was then used to test a path model of the predictors of delinquency and psychological distress and the model shown in Figure 1 was the best fit for the data on a range of indicators. The chi-square was non-significant, the Goodness of Fit Index (GFI) was 0.99, the Comparative Fit Index (CFI) was 0.99, the Normed Fit Index (NFI) was 0.99, and the root mean square error of approximation (RMSEA) was 0.03 all evidence of how closely the model fits the data.

\section{Discussion}

As with previous research this study shows that delinquency in total and in its various forms is subject to age effects. Older children were more likely to have had more involvement in all types of delinquent behaviour than their younger peers. There were also significant age trends in regard to family environment and psychological distress. Older children reported significantly better family relations and personal growth, and seemed significantly better adjusted psychologically reflecting the correlation between family environment and psychological distress generally as shown in Table 3. Boys were significantly more involved in physical aggression, stealing and overall delinquency than girls. In looking at family structure it proved useful to distinguish between single parent families that had always been so, and those that were the consequence of marital breakdown and separation or divorce. The only significant delinquency variables here were stealing and alcohol/drug use and it was those who came from divorced rather than single parent families who scored significantly higher on both. In terms of stealing, those from single parent families scored about the same as those from intact families, while both scored significantly lower than those from divorced families. This would suggest that it is the disruption of the family structure that is important. It is also important to note that family structure does not seem to be implicated, for this sample, in physical aggression, vandalism, or in terms of overall delinquency scores. If overall delinquency scores had been used as the sole outcome

Table 2.

Pearson correlations between delinquency, family environment and psychological distress.

\begin{tabular}{|c|c|c|c|c|c|c|c|c|c|c|}
\hline & 1 & 2 & 3 & 4 & 5 & 6 & 7 & 8 & 9 & 10 \\
\hline \multicolumn{11}{|l|}{1 Physical aggression } \\
\hline 2 Alcohol/drug use & $.57^{* *}$ & & & & & & & & & \\
\hline 3 Vandalism & $.63^{* *}$ & $.48^{* *}$ & & & & & & & & \\
\hline 4 Stealing & $.56^{* *}$ & $.59^{* *}$ & $.60^{* *}$ & & & & & & & \\
\hline 5 Total delinquency & $.84^{* *}$ & $.79^{* *}$ & $.80^{* *}$ & $.86^{* *}$ & & & & & & \\
\hline 6 Family relations & $-.21^{* *}$ & .02 & $-.41^{* *}$ & $-.22^{* *}$ & $-.26^{* *}$ & & & & & \\
\hline 7 Systems maintenance & $-.25^{* *}$ & $-.48_{* *}$ & $-.15^{*}$ & $-.32^{* *}$ & $-.36^{* *}$ & $.21^{* *}$ & & & & \\
\hline 8 Personal growth & $-.37^{* *}$ & $-.39^{* *}$ & $-.36^{* *}$ & $-.40^{* *}$ & $-.46^{* *}$ & $.34^{* *}$ & $.41^{* *}$ & & & \\
\hline 9 Positive Symptom Index & $-.26^{* *}$ & $-.22^{* *}$ & $-.40^{* * *}$ & $-.41^{* *}$ & $-.40^{* *}$ & $-.67^{* *}$ & $-.20^{* *}$ & $-.43^{* *}$ & & \\
\hline 10 Total distress & $-.33^{* *}$ & $-.27^{* *}$ & $-.38^{* *}$ & $-.35^{* *}$ & $-.41^{* *}$ & $-.56^{* *}$ & -.09 & $-.28^{* *}$ & $.68^{* *}$ & \\
\hline 11 General Severity Index & $-.34^{* *}$ & $-.28^{* *}$ & $-.39^{* *}$ & $-.36^{* *}$ & $-.41^{* *}$ & $-.57^{* *}$ & -.09 & $-.29^{* *}$ & $.69^{* *}$ & $.99^{* *}$ \\
\hline
\end{tabular}

${ }^{*} \mathrm{p}<.05,{ }^{* *} \mathrm{p}<.01$. 


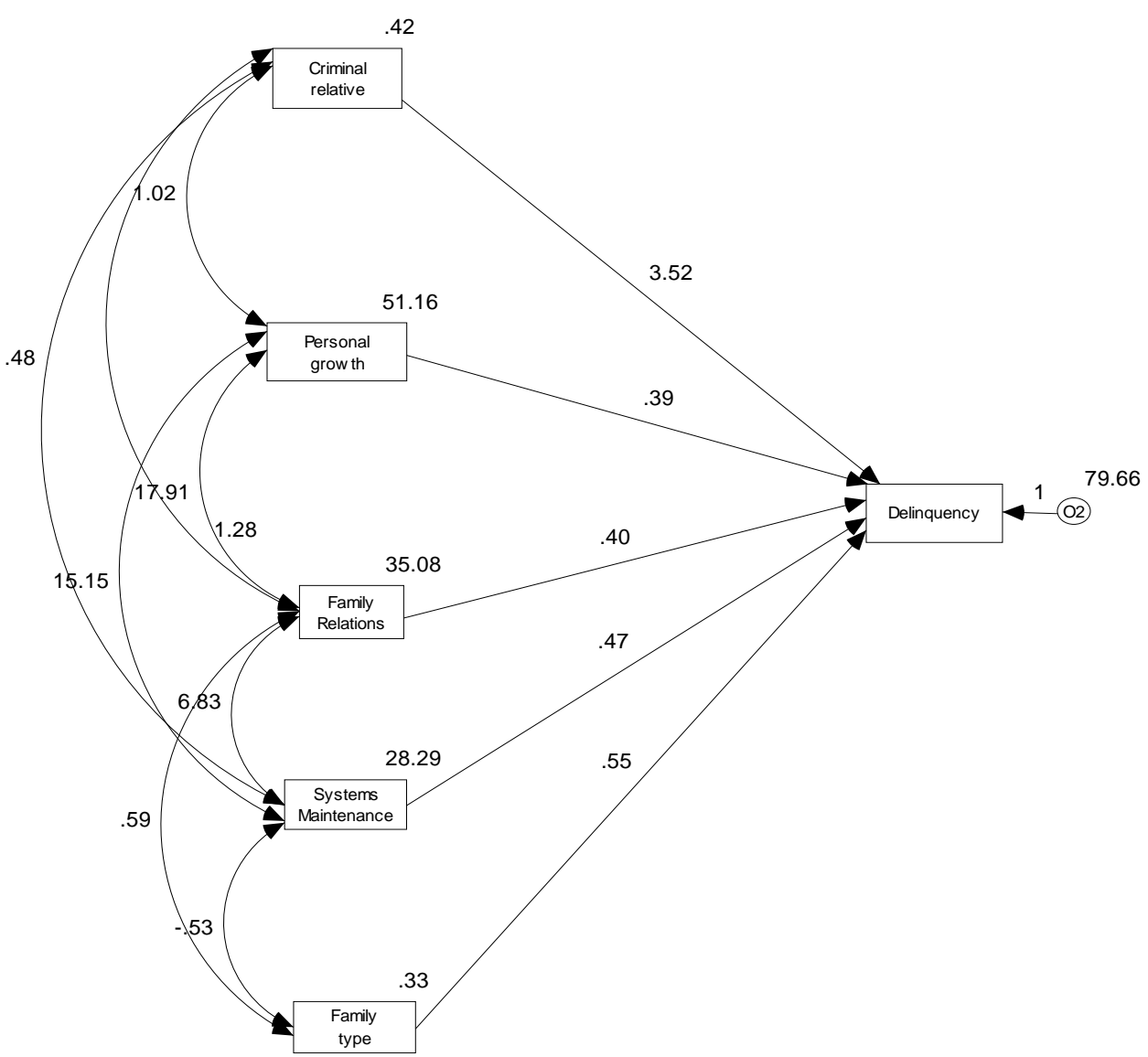

(a)

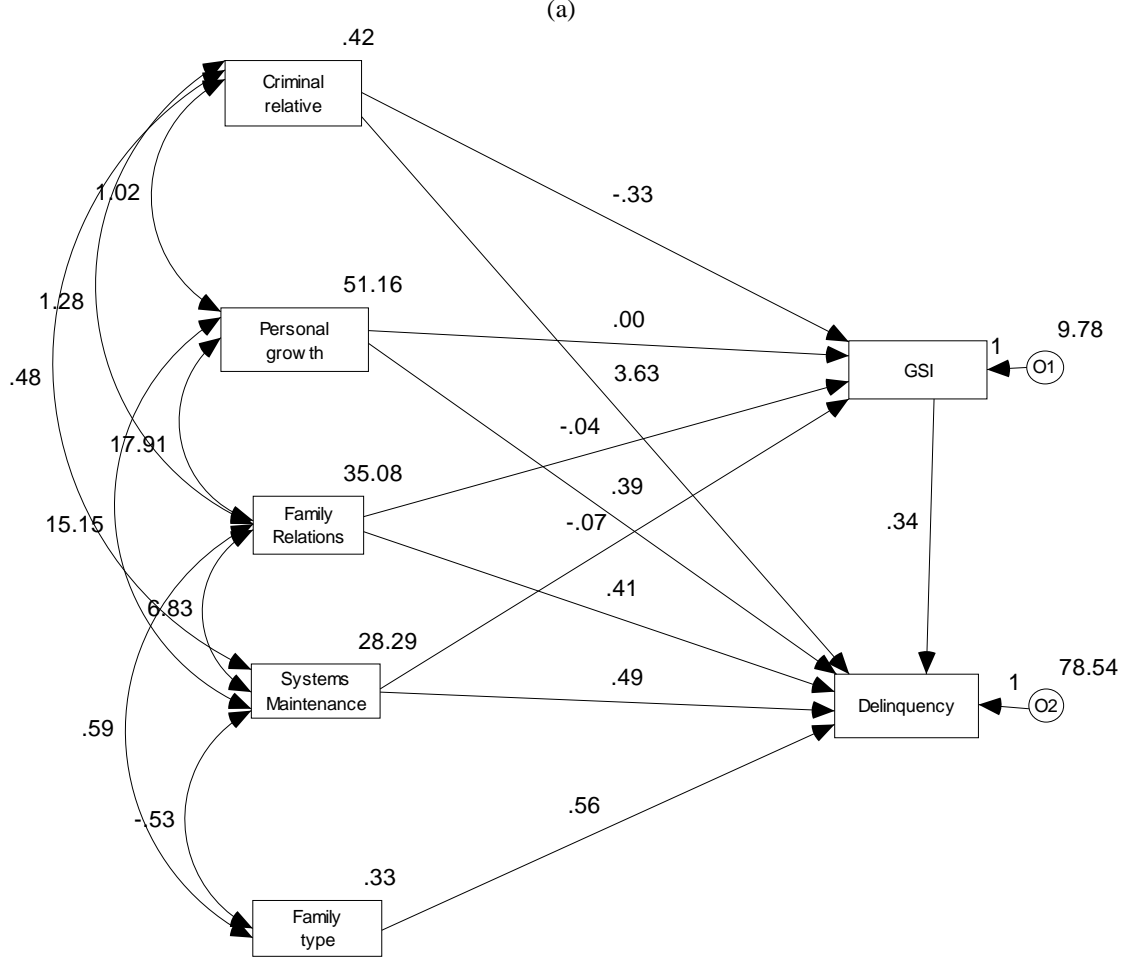

(b)

Figure 1.

(a) Path model of predictors of delinquency from amos structural equation modelling. (chi-square $(d f=2)=$ 3.73, $p=.15 ;$ CFI = 0.99; CFI = 0.99; NFI = 0.99; RMSEA = 0.05); (b) Path model of predictors of psychological distress and delinquency from AMOS structural equation modelling. (chi-square $(d f=3)=3.73, p=.29$; $C F I$ $=0.99 ; G F I=0.99 ; N F I=0.99 ; R M S E A=0.03$ ). 
Table 3.

The significant predictors of delinquency and psychological distress from hierarchical multiple regression analysis.

\begin{tabular}{|c|c|c|c|c|c|c|}
\hline Variable & Beta value & R2 & R2 Change & F value & Probability $<$ & Dependent variable \\
\hline Personal growth & -.22 & .21 & & 58.7 & .001 & \multirow{7}{*}{ Total delinquency } \\
\hline Criminal relative & .20 & .31 & .10 & 48.9 & .001 & \\
\hline General Severity Index & -.24 & .36 & .05 & 40.5 & .001 & \\
\hline Sex & -.20 & .40 & .04 & 36.1 & .001 & \\
\hline Age & .21 & .44 & .04 & 33.7 & .001 & \\
\hline Systems maintenance & -.18 & .47 & .03 & 31.2 & .001 & \\
\hline Personal growth & -.22 & .21 & & 33.3 & .001 & \\
\hline Sex & -.34 & .31 & .10 & 36.6 & .001 & \multirow{5}{*}{ Physical aggression } \\
\hline Criminal relative & .22 & .36 & .05 & 34.2 & .001 & \\
\hline General Severity Index & -.20 & .40 & .04 & 29.3 & .001 & \\
\hline Age & .15 & .44 & .04 & 25.9 & .001 & \\
\hline Family size & -.12 & .47 & .03 & 22.6 & .001 & \\
\hline Family relations & -.17 & .17 & & 44.0 & .001 & \multirow{8}{*}{ Stealing } \\
\hline Personal growth & -.20 & .23 & .06 & 31.8 & .001 & \\
\hline Birth order & .36 & .27 & .04 & 26.8 & .001 & \\
\hline Age & .18 & .31 & .04 & 24.3 & .001 & \\
\hline Family structure & .19 & .35 & .04 & 23.2 & .001 & \\
\hline Family size & -.22 & .38 & .03 & 21.6 & .001 & \\
\hline Criminal relative & .15 & .40 & .02 & 20.0 & .01 & \\
\hline Systems maintenance & -.12 & .41 & .01 & 18.3 & .05 & \\
\hline Criminal relative & .30 & .20 & & 53.3 & .001 & \multirow{3}{*}{ Vandalism } \\
\hline Family relations & -.24 & .28 & .08 & 41.5 & .001 & \\
\hline Personal growth & -.18 & .30 & .02 & 31.2 & .01 & \\
\hline Age & .47 & .24 & & 69.5 & .001 & \multirow{4}{*}{ Alcohol/drug use } \\
\hline Systems maintenance & -.33 & .42 & .18 & 78.9 & .001 & \\
\hline Birth order & .25 & .48 & .06 & 65.6 & .001 & \\
\hline Personal growth & -.16 & .50 & .02 & 52.9 & .01 & \\
\hline Family relations & -.53 & .32 & & 101.6 & .001 & \multirow{4}{*}{ General Severity Index } \\
\hline Alcohol/drug use & .21 & .39 & .07 & 69.9 & .001 & \\
\hline Birth order & -.18 & .42 & .03 & 52.6 & .001 & \\
\hline Criminal relative & .11 & .44 & .02 & 41.2 & .05 & \\
\hline Vandalism & -.21 & .20 & & 53.2 & .001 & \multirow{4}{*}{ Family relations } \\
\hline Criminal relative & -.22 & .26 & .06 & 37.6 & .001 & \\
\hline Stealing & -.20 & .28 & .02 & 28.3 & .01 & \\
\hline Family size & .13 & .30 & .02 & 22.7 & .05 & \\
\hline
\end{tabular}

measure, these effects would not have been seen. It was only because the dimensions of delinquency were looked at separately that it can be suggested that while they do tend to coexist their causes may be substantially different. This is consistent with the complex models suggested by previous research (e.g. Stouthamer-Loeber et al., 2002a, 2002b; Tremblay et al., 1992; Farrigton, 2005).

Family structure does seem to have an effect on family relations and psychological distress in this data. Again single parent families exhibited similar levels of family relations to intact families, both significantly more positive than divorced families. However those from single parent families did exhibit higher levels of psychological distress than either the intact or divorced families. This apparent anomaly may possibly be explained by reference to the negative correlation between psychological distress and delinquency. It would seem that psychological distress and delinquency have different causal roots in families.

One factor that has been shown consistently in the crime literature is the experience of crime through the existence of other criminal members within the family. In fact this is often drawn on as evidence for a 'genetic' theory of criminality. In this study having another family member involved in crime does seem to have a strong effect. Those who reported having a 
criminal relative were significantly more involved in all aspects of delinquency. However the evidence arguably points rather more to a social than a genetic explanation of crime, since these individuals also reported significantly poorer family relations, systems maintenance, and personal growth. However they did not differ significantly on any of the indices of psychological distress. The simplest explanation of this data is that other family member's involvement in crime is disruptive of family relationships, reduces cohesion and increases conflict for example, and provides a model of criminal behaviour for children. This is supported by the fact that the best predictors of family relations are vandalism, having a relative involved in crime, and stealing.

Hierarchical multiple regression analysis clearly demonstrates the differences in relationships between family variables, psychological distress and delinquency. Physical aggression and stealing share a number of important common predictors including personal growth and having a family member involved in crime, but also have a number of other correlates including sex, age and family size. Vandalism however seems most strongly associated with having a family member involved in crime and family relations. On the other hand having a family member involved in crime does not seem to impact on alcohol/drug use. Here age is the major factor with systems maintenance which is indicative of the organisation and discipline in the family. While this study shows some support for previous findings it does suggest that a more complex process related to family relations needs to be invoked in understanding delinquent behaviour.

In conclusion there are a number of important points which are indicated by the current study, despite the limitations of cross-sectional data and self-report measures which must be acknowledged. Firstly there is a point about methodology in that it is important to highlight the need for research in the field to try and separate out various aspects of the complex family and crime variables that are the focus of study. In this research it was beneficial 1) to distinguish between single parent and divorced families, and 2) to consider the dimensions of delinquency separately. The results indicate that while delinquency and psychological distress are both related to family environment they are not likely to be causally related to each other in any meaningful way. Secondly it seems that it is not so much a question of whether a family is intact or not when it comes to delinquency, but whether the family structure has been disrupted. Finally the role of pre-existing criminal involvement in the family does seem to be important in at least two possible ways. One might expect that it provides a model for the child in the social learning sense. However in this study it also appears that it is related to a dysfunctional family environment which may have an impact on delinquent behaviour.

\section{References}

Blackburn, R. (1993). The psychology of criminal conduct: Theory, research, and practice. Chichester: Wiley.

Carey, G. (1992). Twin imitation for antisocial behaviour: Implications for genetic and family environment research. Journal of Abnormal Psychology, 101, 18-25. doi:10.1037/0021-843X.101.1.18

Derogatis, L. R. (1977). SCL-90-R: Administration, scoring and procedures manual. Baltimore, MD: Clinical Psychometric Research

Derogatis, L. R (1993). Brief symptom inventory: Administration, scoring and procedures manual. New York: National Computer Systems.

Fergusson, D. M., Horwood, L. J., \& Lynkskey, M. T. (1994). Parental separation, adolescent psychopathology, and problem behaviours. Journal of the American Academy of Child and Adolescent Psychiatry, 33, 1122-1131. doi:10.1097/00004583-199410000-00008
Fitzgerald, R. (2003). An examination of sex differences in delinquency. Statistics Canada Catalogue Number 85-561-MIE-001. Ottawa.

Glueck, S., \& Glueck, E. (1950). Unravelling Juvenile delinquency. Cambridge, MA: Harvard University Press.

Haapasalo, J., \& Tremblay, R. E. (1994). Physically aggressive boys from ages 6 to 12: Family background, parenting behaviour, and prediction of delinquency. Journal of Consulting and Clinical Psychology, 62, 1044-1052. doi:10.1037/0022-006X.62.5.1044

Hetherington, E. M., Cox, M., \& Cox, R. (1985). Long-term effects of divorce and remarriage on the adjustment of children. Journal of the American Academy of Psychiatry, 24, 518-830. doi:10.1016/S0002-7138(09)60052-2

Hirsch, N. D. M. (1937). Dynamic causes of juvenile crime. Cambridge, MA: Sci-Art Publishers.

Kakar, S. (2005). Gang membership, delinquent friends and criminal family memebers: Determining the connections. Journal of Gang Research, 13, 41-52.

LeBlanc, M., \& Tremblay, R. E. (1988). A study of factors associated with the stability of hidden delinquency. International Journal of Adolescence and Youth, 1, 269-291.

Lindner, M. S., Stanley-Hagen, M., \& Cavanaugh B. J. (1992). The adjustment of children in non-divorced, divorced, single-mother, and remarried families. Monographs of the Society for Research in Child Development, 57, 35-72. doi:10.1111/j.1540-5834.1992.tb00302.x

Mack, K. Y., Leiber, M. J., Featherstone, R. A., \& Monserud, M. A. (2007). Reassessing the family-delinquency association: Do family type, family processes, and economic factors make a difference? Journal of Criminal Justice, 35, 51-67. doi:10.1016/j.jcrimjus.2006.11.015

Moffit, T. (2005). The new look of behavioural genetics in developmental psychopathology: Gene-environment interplay in antisocial behaviour. Psychological Bulletin, 131, 533-554. doi:10.1037/0033-2909.131.4.533

Moos, R. H., \& Moos, B. S. (1986) Family environment scale manual (2nd ed.). Palo Alto, CA: Consulting Psychologists Press

Nader, D., Singleton, N., \& Meltzer, H. (2003). Psychiatric morbidity among young offenders in England and Wales. International Review of Psychiatry, 15, 144-147. doi:10.1080/0954026021000046074

Pagani, L., Tremblay, R. E., Vitaro, F., Kerr, M., \& McDuff, P. (1998). The impact of family transition on development of delinquency in adolescent boys: A 9-year longitudinal study. Journal of Child Psychology and Psychiatry, 39, 489-499. doi:10.1017/S0021963098002200

Smith, C. A., \& Farrington, D. P. (2004). Continuities in antisocial behaviour and parenting across three generations. Journal of Child Psychology and Psychiatry, 45, 230-247. doi:10.1111/j.1469-7610.2004.00216.x

Stouthamer-Loeber, M., \& Loeber, R. (1988). The use of prediction data in understanding delinquency. Behavioural Sciences \& the Law, 6, 333-354. doi:10.1002/bsl.2370060305

Stouthamer-Loeber, M., Loeber, R., Wei, E., Farrington, D., \& Wikstrom, P.-O. H. (2002a). Risk and promotive effects in the explanation of persistent serious delinquency in boys. Journal of Consulting and Clinical Psychology, 70, 111-123. doi:10.1037/0022-006X.70.1.111

Stouthamer-Loeber, M., Wei, E. H., Homish, D. L., \& Loeber, R. (2002b). Which family and demographic factors are related to both maltreatment and persistent juvenile delinquency? Children's Services: Social Policy, Research and Practice, 5, 261-272. doi:10.1207/S15326918CS0504_3

Taylor, K. A. (2001). On the explanatory limits of behavioural genetics. In D. Wasserman, \& R. Wachbroit (Eds.), Genetics and criminal behaviour. New York: Cambridge University Press.

Tremblay, R. E., Maasse, B., Perron, D., Leblanc, M., Schwartzman, A. E., \& Ledingham, J. E. (1992). Early disruptive behaviour, poor school achievement, delinquent behaviour, and delinquent personality: Longitudinal analyses. Journal of Consulting and Clinical Psychology, 60, 64-72. doi:10.1037/0022-006X.60.1.64

Tuvblad, C., Grann, M., \& Lichtenstein, P. (2006). Heritability for adolescent antisocial behaviour differs with socioeconomic status: Gene-environment interaction. Journal of Child Psychology and Psychiatry, 47, 734-743. doi:10.1111/j.1469-7610.2005.01552.x 